\title{
ANATOMICAL ASSESSMENT OF MAIZE (ZEA MAYS L.) SEEDLINGS EXPOSED TO COLLOIDAL SILVER NANOPARTICLES
}

\author{
JAFARI, S..$^{*}$-DAVOOdI, D. ${ }^{2}$ - JONOUBI, P. ${ }^{1}-$ MAJD, A. ${ }^{1}$ - AlIZADEH, H. ${ }^{3}-$ SHOBBAR, Z.-S. ${ }^{2}$ \\ ${ }^{I}$ Department of Plant Sciences, Faculty of Biological Sciences, Kharazmi University, \\ Tehran, Iran \\ ${ }^{2}$ Agriculture Biotechnology Research Institute of Iran, Karaj, Iran \\ ${ }^{3}$ Department of Agronomy and Plant breeding, Faculty of Agricultural Science and \\ Engineering, University of Tehran, Karaj, Iran \\ *Corresponding author \\ e-mail: std_sudabejafari@khu.ac.ir, sudabe.jafari@gmail.com \\ (Received $4^{\text {th }}$ Jan 2018; accepted $16^{\text {th }}$ Apr 2018)
}

\begin{abstract}
Due to the widespread use of silver nanoparticles (nAg) in different products, the possibility of their leakage into the environment has been increasing. It is, therefore, crucial to study the possible effects of $\mathrm{nAg}$ on plants as the key components of ecosystems. In the present study, the effects of different concentrations of colloidal $\mathrm{nAg}$ on sweet maize were investigated at the anatomic level. Using dynamic light scattering and electron microscopy, the size of the $\mathrm{nAg}$ was estimated less than $80 \mathrm{~nm}$. After one week of treatment, thin cross sections of roots and shoots were prepared and studied by light and fluorescence microscopes. Results showed that cortex and vascular cylinder area of roots and shoots of treated plants significantly $(\mathrm{P}<0.05)$ decreased versus control. Significant $(\mathrm{P}<0.05)$ reduction in diameter of metaxylem vessels was also identified. In addition, deform cells and $\mathrm{Ag}$ accumulations in root tissues of treated seedlings were observed. The results of this study indicate that $\mathrm{nAg}$ can enter into plant root and make considerable adverse effects on the plant root anatomy suggesting that $\mathrm{nAg}$ can become a future emerging pollutant.
\end{abstract}

Keywords: auto fluorescent, bioaccumulation, metaxylem, micrograph, uptake

\section{Introduction}

Due to their small size $(1-100 \mathrm{~nm})$ and the increase in their surface-to-volume ratio, nanoparticles have special properties making them suitable for various practical applications. Nowadays, variety of engineered nanoparticles are being used to make a wide range of products including personal care products, next-generatin batteries and solar cells, and environmental remediation of water, sediments, and soil (Buzea et al., 2017). Therefore, the particle's exposure to the environment and plants has been drastically increasing. Researchers are trying to carefully assess the risks and potential effects of nanoparticles on plants and humans and animls health and to propose methods to prevent or reduce the contamination of the environment with nanoparticles as emerging pollutants (Ghorbanpour et al., 2017).

Among various engineered nanoparticles, silver nanoparticles (nAg) due to their special properties (antimicrobial, electrical, optical and catalytic), have found applications in industries (Sintubin et al., 2012). Nowadays, engineered silver nanoparticles are used to make products such as food packages, textiles, electronic devices, home appliances, cosmetics, medical devices, water disinfectants, sprays (Varner et al., 2010), and also to produce pesticides (Thul et al., 2013). Increasing the 
production and use of products containing nAg will eventually lead to an increase in the probable release of these particles to the environment from production to disposal/reuse precedures; so there is an urgent need to study the effects of engineered nanoparticles on plants which are the important members of ecosystems and food chain.

The effects of nanoparticles can be investigated at different levels in plants. These effects can vary according to size, shape, and concentration of nanoparticles, and age, and species of plants (Rico et al., 2011). In recent years, numerous research studies have been carried out on the effects of nanoparticles on plants and toxic effects of $\mathrm{nAg}$ have been reported. For example, cytotoxicity and genotoxicity in onion (Allium cepa L.) and broad bean (Vicia faba L.) roots treated with nAg have been observed by decreasing in mitotic index and chromosomal aberrations (Kumari et al., 2009; Patlolla et al., 2012). Mustante and White (2012) reported a decrease in biomass of pumpkin (Cucurbita pepo L.) plants treated with $\mathrm{nAg}$. Wang et al. (2013) reported toxic effects of $\mathrm{nAg}$ accumulated in poplar (Populus deltoides $\times$ nigra) and arabidopsis (Arabidopsis thaliana (L.) Heynh.) on evapotranspiration. Also, uptake of nAg by roots and transport to the shoots was observed in arabidopsis (Geisler-Lee et al., 2014). However, the mechanisms of the nAg impacts and their targets in plants are not adequately studied in the literature hence more research needs to be done at different levels such as anatomical, cytological, cytogenetical and molecular.

At anatomical level there are only few research studies on the impacts of nanoparticles. For instance, Thuesombat et al. (2014) reported low impact on the leaf anatomy of rice (Oryza sativa L.) plants treated with $\mathrm{nAg}(20 \mathrm{~nm} ; 10 \mathrm{ppm})$, while a significant change was observed at $100 \mathrm{ppm}$ concentrations in the anatomical traits. This study demonstrated that the effects of nanoparticle were concentration dependent. Pokhrel and Dubey (2013) also studied the number of metaxylem vessels (a type of transport tissue in vascular plants) in the primary root of maize exposed to $75 \mathrm{ppm}$ of citrate coated $\mathrm{nAg}$. They reported an increase in the number of metaxylem vessels in treated plants. In the study of Mousavi Kouhi et al. (2015), significant changes were observed in the anatomy of leaf and root of canola (Brassica napus L.) treated with zinc oxide nanoparticles.

Due to the paucity of the research on anatomical responses of plants exposed to nanoparticles, in this paper, the effects of $\mathrm{nAg}$ on maize seedlings at anatomical level were investigated. In addition to being an important crop, maize is considered to be a model plant in the environmental and genetic studies (Strable and Scanlon, 2009). It is worth noting that silver is an unnecessary element with unknown physiologically functions in plants. However increasing the concentration of the element to a certain extent can be fatal for plants.

\section{Materials and Methods}

\section{Preparing suspensions and solutions}

Coloidal nAg with a concentration of 4000 ppm (NanoSilver-W4000) GEBER was purchased fromBaran Chemistry Pasargad Company. The size of the nanoparticles was measured with the dynamic light scattering (DLS) method (Figure 1A) and with a particle size analyser device (Particle Metrix GmbH, Germany) less than $80 \mathrm{~nm}$. Also, the shape and size of the nanoparticles were examined by a high resolution field emission scanning electron microscope (FE-SEM) (MIRA3 TE SCAN, Czech 
Republic) (Figure 1B). Using distilled water, concentrations of 300, 200, and $100 \mathrm{ppm}$ were prepared from a homogenous suspension of $4000 \mathrm{ppm}$. The homogeneity of the suspensions was also maintained after dilution.

Since studies have shown that part of the $\mathrm{nAg}$ effects is due to the release of silver ions from them (Mcshan et al., 2014), in this study, silver nitrate was used as silver ion and positive control for comparison. The silver nitrate solution, as a positive control, was made from white powder of silver nitrate (Sigma-Aldrich) and distilled water at concentrations of 300, 200, and $100 \mathrm{ppm}$. For the sake of brevity, in the rest of the paper, $\mathrm{nAg} 1, \mathrm{nAg} 2, \mathrm{nAg} 3, \mathrm{AgN} 1, \mathrm{AgN} 2$, and $\mathrm{AgN} 3$ have been used correspond to the treatments with $\mathrm{nAg}$ of 100,200 , and $300 \mathrm{ppm}$ and with silver nitrate of the same concentrations, respectively.

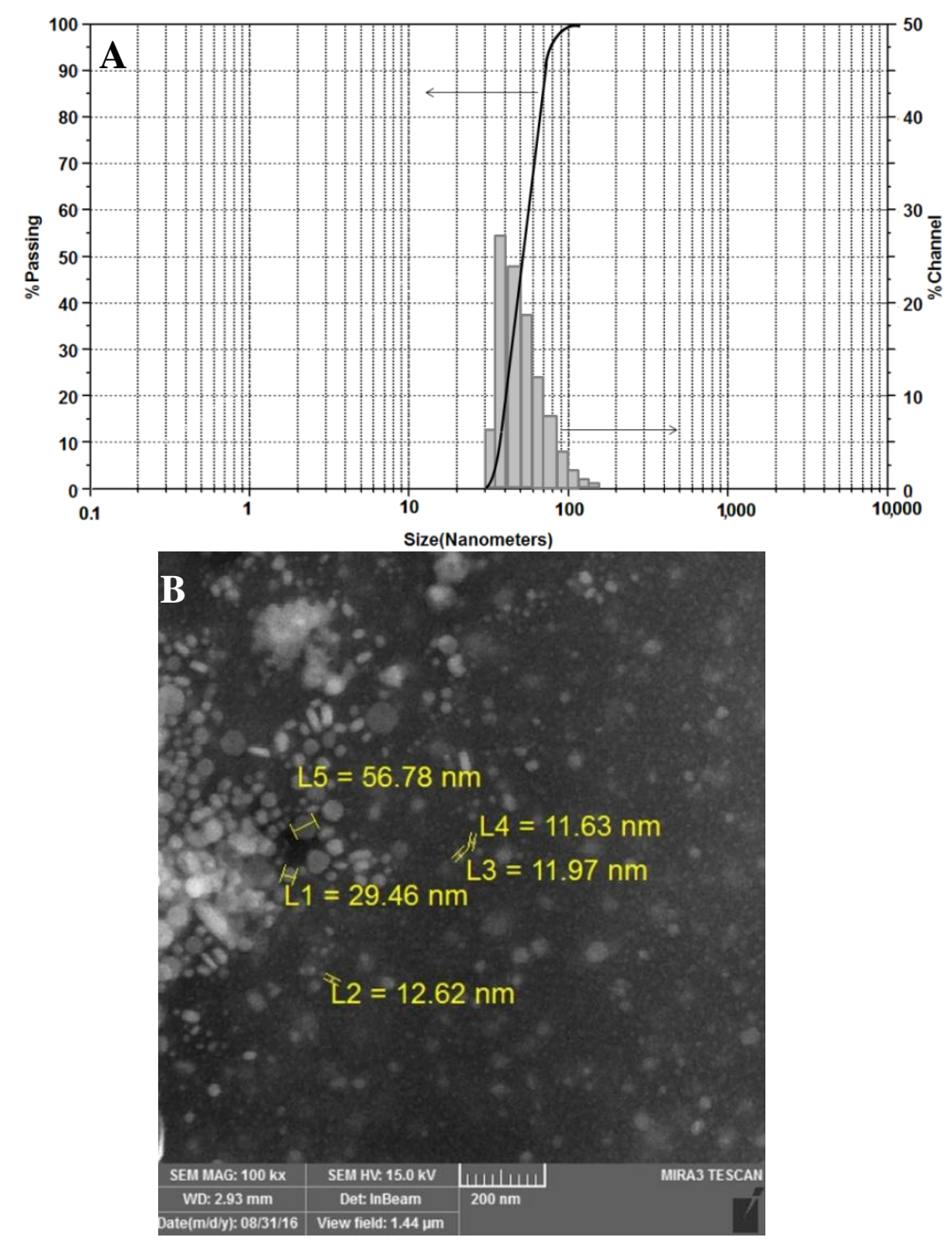

Figure 1. A) The dynamic light scattering graph and B) the field emission scanning electron (FE-SEM) micrograph of the colloidal nAg (NanoSilver-W4000) GEBER show that the size of these spherical particles is less than $80 \mathrm{~nm}$.

\section{Seeds}

The sweet maize (Zea mays L. var. Saccharata 'Ksc 403') seeds were obtained from the Seed and Plant Improvement Research Institute, Karaj, Iran. In order to reduce the probability of contamination, the seeds were first put in ethanol $70 \%$ for 30 seconds and 
then rinsed three times with sterile distilled water. Thereafter they were immersed in sodium hypochlorite $5 \%$ solution for 10 minutes. Next, they were rinsed three times with sterile distilled water (Rao et al., 2006). Decontaminated seeds were laid in Petri dishes on sterile filter papers. Petri dishes containing seeds and $15 \mathrm{~mL}$ distilled water were incubated in dark at $25{ }^{\circ} \mathrm{C}$ for one week.

\section{Seedling's treatments}

Triplicates of seven-day-old seedlings with equal size were selected for a completely random design experiment. $\mathrm{nAg}$ suspension and silver nitrate solution were poured into the $15 \mathrm{~mL}$ tubes. Distilled water was used as the negative control. The entrance of the tubes was covered by a selefon with a small hole in its center so that only the seedling's root could be passed through it. In this condition, the seed and shoot were not directly in contact with the contents of the tube. In order to prevent the effect of light exposure, the tubes were covered by aluminum foil. The seedlings were exposed to daily photoperiod of 16 hours of light and eight hours of darkness at $25{ }^{\circ} \mathrm{C}$ for one week.

\section{Anatomical analyses}

For anatomical studies, the root and shoot were isolated separately and fix in the ethanol 70\%:glycerol. Using regular flat shaving razor blades, thin cross sections of roots and shoots were obtained from the root cellular maturation zone and $2 \mathrm{~cm}$ above the crown of shoot, respectively. For staining, the sections were immersed in toluidine blue $0.5 \%$ (in phosphate buffer) for 20 seconds and then rinsed with tap water. The specimens were studied with an optical microscope (Olympus). Due to the fact that some of the cell wall componds (e.g. phenolic compounds), are auto-fluorescent (Mylle et al., 2013), some specimens were studied without staining to evaluate the possible changes in their fluorescence properties using a fluorescent microscope (E800-Nikon, Japan). Digital images were made from the slides and the cortex area, vascular cylinder area, the ratio of cortex area to the vascular cylinder area, and the diameter of openings of metaxylems were calculated using Image Tool software V. 3.0 calibrated by a micrometer slide.

\section{Data analysis}

Analysis of variance (ANOVA) $(\mathrm{P}<0.05)$ was performed using SPSS ver.18 software and the Duncan test was used to diagnose the different means. Charts were plotted using MATLAB software.

\section{Results}

Figure 2 shows non-stained transverse sections of the primary roots for controls and treatments. The cross-section of negative control seedling's root demonstrates that, from outside to inside, there are root hairs, epidermis, cortex parenchyma, endodermis, a layer of pericycle cells, bundles of phloem, protoxylems, metaxylems, and the pith. As is seen in this figure, the pith cells are spherical and the walls of endodermal cells are thicker on the three sides ( $U$ thickening). Also, the number of metaxylam cells in the majority of the sections was counted 6 and 7, the xylems and phloems are in alternative order, the type of stele is medullated protostele, and the arrangement of xylems is 
exarch. In the cross-sections of the roots treated with nAg100, black areas in the root hairs and epidermis are observed. The black region in the corresponding positive control sections (AgN100) are visible from the epidermis to endodermis. In the cross sections of roots treated with $\mathrm{nAg} 200$, black areas are visible in the cortical parenchyma and from the sites of emergence of lateral root primordia to the pricycle cells. In its corresponding positive control (AgN200) sections, in addition to the cortex, the black areas are visible around the metaxylems. In the transverse sections of primary roots at the highest concentration of the study (nAg300), black accumulations are visible in the vascular cylinder cells and the protoxylem cells and the bundles of phloem vessels are deformed and distorted. Also, the pith cells are darkened and deformed. The primary root sections of its corresponding positive control (AgN300), exhibit greater amounts of silver penetration. The black areas and accumulations from the epidermis to the pith cells are visible. Here, the shape of the cells is normal in bundles of phloem vessels.
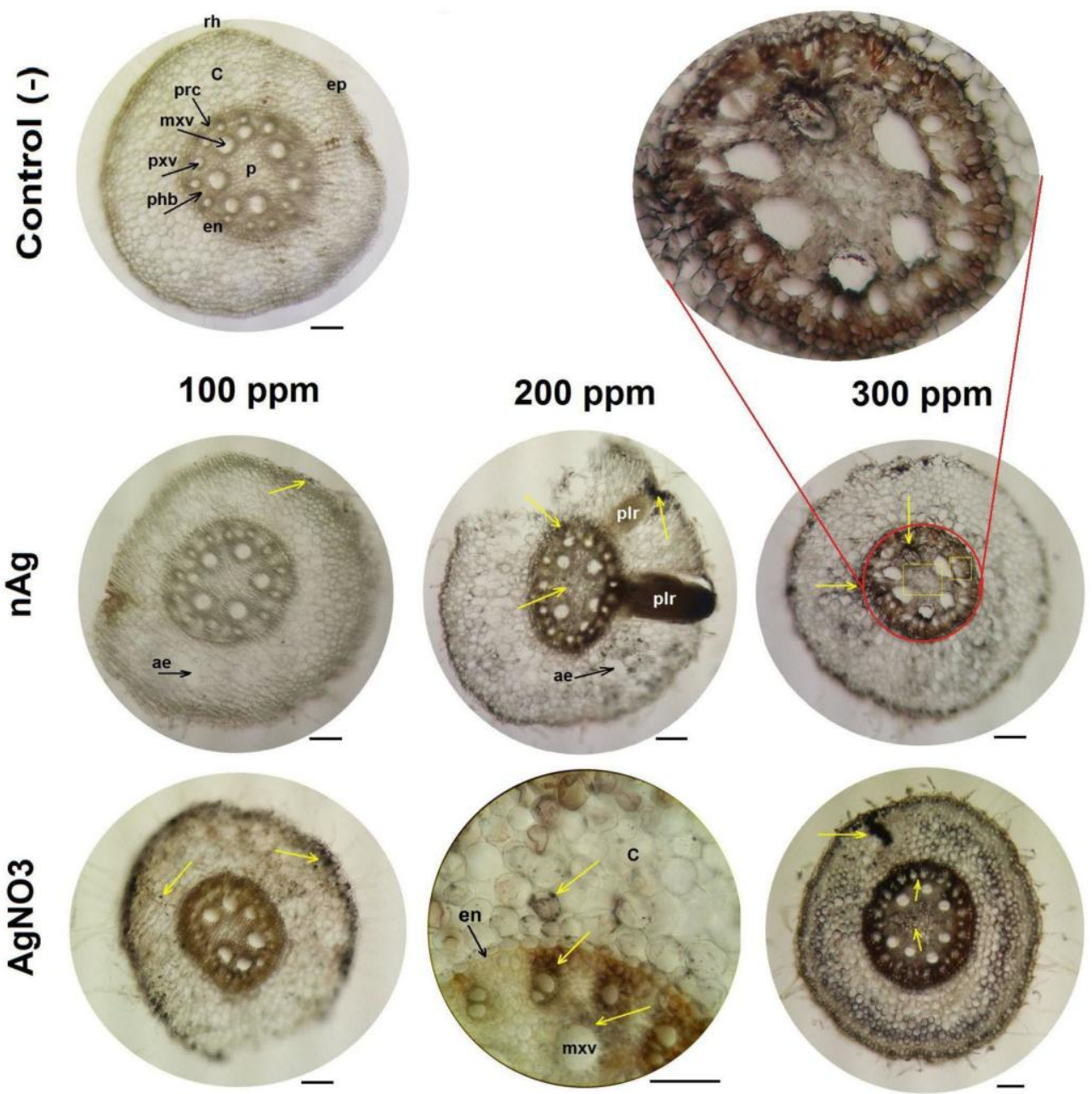

Figure 2. Light micrographs represent impacts of silver treatments on maize primary root in non stained transverse sections. Light arrows indicate selected dark region of silver accumulation. ae: aeranchyma, c: cortex, en: endodermis, ep: epidermis, mxv: metaxylem vessel, p: pith, phb: phloem bundle, plr: primordium of lateral root, pxv: protoxylem vessel, prc: pericycle, rh: root hair. The labels in $n \mathrm{Ag}$ and $\mathrm{AgNo}_{3}$ treatments are the same as the control labels. Bars $=100 \mu \mathrm{m}$. All photos are portions of mature zone of maize primary roots. Notice the irregular shape of pith cells and xylem and phloem vessels in magnified image of vascular cylinder of nAg treatment (300 ppm). 
The fluorescent micrographs of Figure 3 demonstrate the auto-fluorescent properties of the cell walls of the control and treated roots. In these images the walls of endodermal cells with U-shaped thickening are more reflective and distinguishable from the pericycle and cortical cells. As seen, in $\mathrm{nAg} 300$, the accumulation of silver prevents the reflection of light from the thick walls of endodermal cells. Furthermore these micrographs show that by increasing the concentration there is more penetration of $\mathrm{Ag}$ into root tissues resulting in less light reflection.
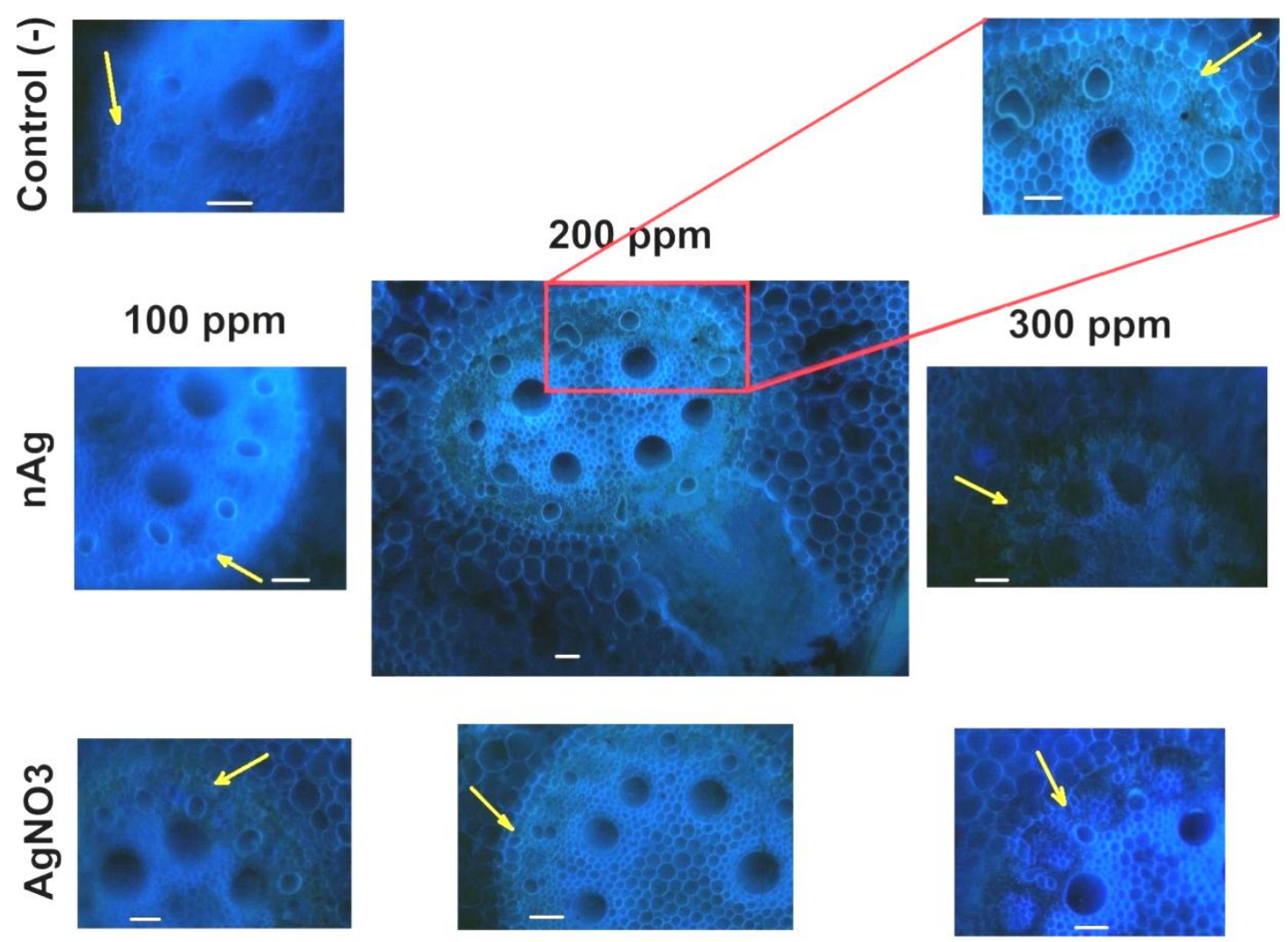

Figure 3. The Fluorescent micrographs of non stained transverse sections of maize primary roots exposed to silver treatments. Arrows indicate $U$ thickening of endodermis cell walls. In $n A g 300$ ppm treatment, silver accumulation reduced light reflection; Bars $=50 \mu \mathrm{m}$

As seen in Figure 4 in the cross section prepared from mesocotyls of shoots, from outside to inside, there are epidermis, cortical parenchyma, endodermis, and vascular cylinder. The vascular cylinder here, in contrast to the transverse section of roots, is not completely circular. Also, adventitious roots are observed in some sections (Figure 4A). There is no significant morphological difference in the mesocotyl sections of $\mathrm{nAg} 100$ treated seedlings compared to negative and positive controls (Figure 4B, C). Also, in the nAg200 and nAg300 treatments, and in their corresponding positive control, there was no significant morphological difference in the shoot transverse sections to negative control. 

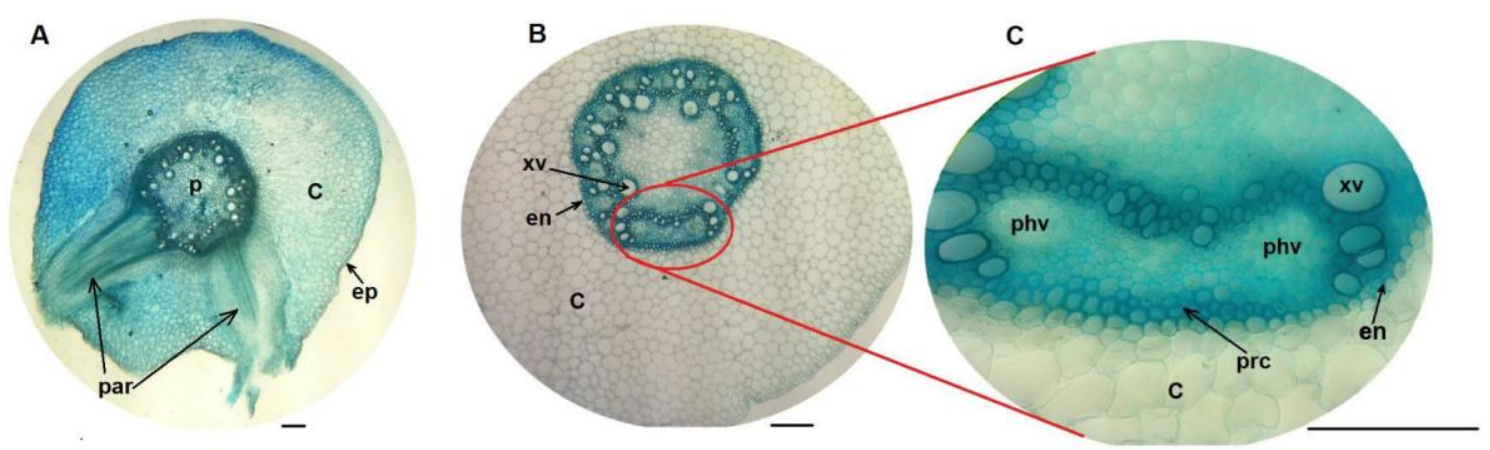

Figure 4. The light micrographs represent transverse sections of two weeks old maize shoots(mesocotyl). Sections were prepared from two centimeters above the crown. A) Negative control, B) $n A g 100$ ppm treatment, C) magnification of one part of the vascular cylinder.c: cortex, en: endoderm, ep: epiderm, p: pith, par: primordium of adventitious root, phv: phloem vessel, prc: pericycle, xv: xylem vessel. Bars $=100 \mu \mathrm{m}$

As Figure 5A shows, there is not significant difference $(\mathrm{P}<0.05)$ between the means of cortex area of negative control and nAg100 treatment, however there is $88 \%$ significant increase versus its corresponding positive control. Also, there is no significant difference between the means of vascular cylinder and the ratio of cortex to the vascular cylinder area with negative control $(\mathrm{P}<0.05)$ (Figure $5 B, C)$. The number of metaxylem in this treatment and in the corresponding positive control were counted 6 . In the case of shoots, the means of the cortex and the the vascular cylinder area relative to the negative control is reduced 19 and 47\%, respectively (Figure5A, B). However, the ratio of cortex to vascular cylinders area is $53 \%$ higher than negative control (Figure 5C).

According to Figure 5A, B, the means of the cortex and the vascular cylinder area of the root treated with nAg200 versus negative control is respectively 35 and $29 \%$ higher. In the later treatment there is no significant difference between the means of ratio of cortex to vascular cylinder area. Compared to the corresponding positive control, the means of the cortex and vascular cylinder area is respectively 53 and $41 \%$, higher in nAg200 treatment (Figure A, B5). The number of metaxylem vessels in this treatment are 5, 6 and 7, and in the corresponding positive control, 6 . The shoot cortex area and the vascular cylinder area were $64 \%$ and $27 \%$, higher than negative control respectively, and $66 \%$ and $86 \%$ less than the corresponding control, respectively (Figure 5A, B). The ratio of areas versus negative and positive controls is reduced $30 \%$ and $10 \%$, respectively (Figure 5C).

Figure $5 A, B$ shows that the average of the root cortex and vascular cylinder area in nAg300 treatment is $46 \%$ and $39 \%$ lower than the negative control, respectively. In this treatment, the mean area of the vascular cylinder is $32 \%$ less than the corresponding positive control (AgN300). There is no significant difference between means of the ratio of cortex area to vascular cylinder area (Figure 5C). The number of metaxylem vessels in this treatment was 6 and in the corresponding positive control, 7 and 8 . The mean of shoot cortex area and vascular cylinder area in this treatment is 29 and $26 \%$ less than negative control respectively (Figure A, B5). The ratio of areas is $23 \%$ less than the corresponding positive control, and there is no significant difference with the negative control (Figure C5). 

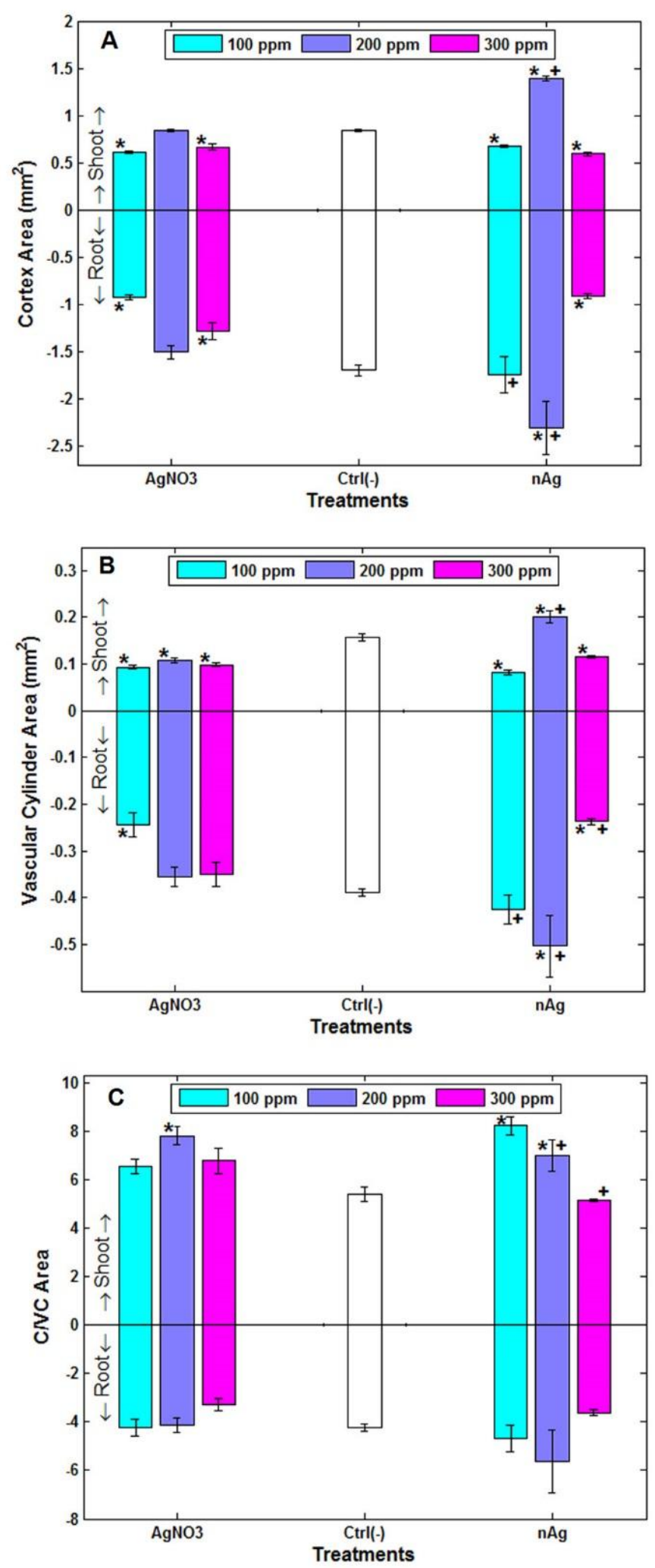

Figure 5. The means $\pm S E$ of shoot and root A)cortex area, B) vascular cylinder area and $C$ ) cortex to vascular cylinder area of the controls and treated seedlings. Significant differences ( $p$ $<0.05)$ have been shown according to Duncan's test *:versus negative control and $+:$ versus corresponding positive control. C: cortex, Ctrl(-): negative control (distilled water), VC: vascular cylider 
The means of metaxylem opening diameter are provided in Table 1. As presented in the nAg100 treatment xylem diameter is less than the negative control and more than the corresponding positive control. The mean of metaxylem's diameter in the nAg200 treatment is less than negative control and does not have a significant difference with the corresponding positive control. The diameter of the metaxylem vessels is significantly less than the negative control and is more than the corresponding positive control in nAg300 treatment.

Table 1. The means $\pm S E$ (in micrometer) of metaxylem diameter of the controls and treated 14-day-old maize seedling roots. Significant differences $(p<0.05)$ have been shown according to Duncan's test *: versus negative control (distilled water) and +: versus correspondence positive control (silver nitrate). Numbers in parentheses indicate concentrations in ppm

\begin{tabular}{|c|c|c|c|c|c|c|}
\hline $\begin{array}{c}\mathrm{AgNO}_{3} \\
(\mathbf{1 0 0 )}\end{array}$ & $\begin{array}{c}\mathrm{AgNO}_{3} \\
(200)\end{array}$ & $\begin{array}{c}\mathrm{AgNO}_{3} \\
(\mathbf{3 0 0})\end{array}$ & Control (-) & $\begin{array}{c}\mathrm{nAg} \\
(\mathbf{1 0 0})\end{array}$ & $\begin{array}{c}\mathrm{nAg} \\
(200)\end{array}$ & $\begin{array}{l}\mathbf{n A g} \\
(\mathbf{3 0 0})\end{array}$ \\
\hline $\begin{array}{c}79.70 \pm \\
1.97^{*}\end{array}$ & $\begin{array}{c}78.57 \pm \\
2.15^{*}\end{array}$ & $\begin{array}{c}64.97 \pm \\
3.79^{*}\end{array}$ & $\begin{array}{c}109.65 \pm \\
5.65\end{array}$ & $\begin{array}{c}94.15 \pm \\
2.20^{+*}\end{array}$ & $\begin{array}{l}78.57 \pm \\
2.63^{*}\end{array}$ & $\begin{array}{c}89.43 \pm \\
2.25^{+*}\end{array}$ \\
\hline
\end{tabular}

Values are mean \pm SE

\section{Discussion}

The results of this study indicated that $\mathrm{Ag}^{0} / \mathrm{Ag}^{+}$was uptaken by the maize primary roots. Observation of black aggregates in micrographs of transverse sections of seedling's roots treated with $\mathrm{nAg}$ and silver nitrate showed that silver could enter into the roots. According to the observations, $\mathrm{nAg}$ entered more through the apoplastic pathway and intercellular free spaces and less through symplastic pathway (across cytoplasm) to the root tissues and were accumulated there or entered the emptied cellular elements of vessels via water uptake. It should be noted that as described by Zhao et al. (2012) nanoparticles may enter through natural nano or micro-size pores of plant cell walls. However, the size of the particles used in this study was greater than the size of the cell wall pores of maize primary root which are about $6.6 \mathrm{~nm}$ as estimated by Asli and Neumann (2009). The study of transverse sections with fluorescence microscopy showed that the accumulation of silver or the combination of silver with other molecules in endodermal cells at the highest concentration of the present study reduced light reflection.

Qualitative traits, for example, the shape of cells at the highest concentration used in this study (nAg300), have undergone dramatic changes in the vascular cylinder of the root so that the cells of the phloem vessels became distorted (Figure 2). Also, the opening of the xylems in the transverse sections are not circular anymore. Silver aggregates appear to have a mechanical pressure on the vascular cylinder cells. These changes can also be due to the interaction of $\mathrm{nAg}$ with cell wall components. Rico et al. and Dietz and Herth (2011) also noted that nanoparticles due to their small size and high surface activity can interact with cell structures and components. Not observing these changes in silver nitrate treatments with a corresponding concentration reflects the different effects of nAg.

Micrometrics measurements showed significant reduction in root and shoot cortex area and the vascular cylinder area versus negative control in all treatments except for nAg200. However, the ratio of areas in the root has no significant difference with negative control. The observed differences in the measured traits in the nAg200 
treatment as well as the study of non-stained cross sections suggests that it is due to the absorption of different amounts of silver. In other words, silver absorption was not linear as many factors could influence it. For example, nanoparticles are more likely to penetrate from the sites of lateral root emergence as in these sites the integrity of root tissues is lost.

The number of metaxylems in the root transverse sections of all treatments was similar to the negative control and was 6 or 7. Only in nAg300 treatments 8 metaxylems were observed. Furthermore, a significant reduction of xylem's opening diameter was observed in all treated roots versus control. These results suggest that silver could affect the anatomical traits of root tissues specially the transport tissues. The small proportion of the root vascular cylinder to the cortex area indicates that the $\mathrm{Ag}^{0} / \mathrm{Ag}^{+}$uptaken by the roots cause interference in water and nutrients transportation and as shown in Figures 2 and 3, lead to death of many root cells. However, there were no significant difference in the anatomical traits of the shoots of treated seedlings. According to the results the behavior of $\mathrm{nAg}$ is relatively similar to that of silver nitrate suggesting that part of the $\mathrm{nAg}$ impacts is by releasing of silver ions from them.

\section{Conclusion}

The results of this study show that $\mathrm{nAg}$ can be absorbed by maize root and subsequently affect the growth of the shoots. Accumulation, mechanical stress, and interaction with cell wall components are the possible mechanisms for the effect of nanoparticles used in this study. Moreover, the findings of this research demonstrate the usefulness of anatomical traits (alongside the study of effects at other levels) for evaluating the effects of nanomaterials in plants. The results of this reseach could raise concerns over possible nAg leakage into the environment and human health risks. The authors plan to explore other stages of maize life in treatment with different size and concentrations of $\mathrm{nAg}$.

Acknowledgements. The authors would like to appreciate the Iran Nanotechnology Initiative Council for their supports. Dr. Somaye Jafari in Institute of Nano Science and Nano technology of Sharif University of Technology is also acknowledged for her assistance in using MATLAB software.

\section{REFERENCES}

[1] Asli, S., Neumann, P. M. (2009): Colloidal suspensions of clay or titanium dioxide nanoparticles can inhibit leaf growth and transpiration via physical effects on root water transport. - Plant Cell and Environment. 32: 577-584.

[2] Buzea, C., Pacheco, I. (2017): Nanomaterial and nanoparticle: Origin and activity. - In: Ghorbanpour, M., Manika, K., Varma, A. (eds.) Nanoscience and Plant-Soil Systems. Soil Biology, Springer, Cham.

[3] Dietz, K.J., Herth, S. (2011): Plant nanotoxicology. - Trends in Plant Science 16(11): 582-589.

[4] Geisler-Lee, J., Brooks, M., Gerfen, J. R., Wang, Q., Fotis, C., Sparer, A., Ma, X., Berg, R. H., Geisler, M. (2014): Reproductive toxicity and life history study of silver nanoparticle effect, uptake and transport in Arabidopsis thaliana. - Nanomaterials 4: 301318. 
[5] Ghorbanpour, M., Manika, K., Varma, A. (2017): Nanoscience and Plant-Soil Systems. Soil Biology. - Springer, Cham

[6] Kumari, M., Mukherjee A., Chandrasekaran N. (2009): Genotoxicity of silver nanoparticles in Allium cepa. - Science of the Total Environment 407: 5243-5246.

[7] Mcshan, D., Ray, P. C., Yu, H. (2014): Molecular toxicity mechanism of nanosilver. Journal of Food Drug Analysis 22: 116-127.

[8] Mousavi Kouhi, S. M., Lahouti, M., Ganjeali, A., Entezari, M.H. (2015): Long-term exposure of rape seed (Brassica napus L.) to $\mathrm{ZnO}$ nanoparticles: anatomical and ultrastructural responses. - Environmental Science and Pollution Research 22(14):1073310743.

[9] Mustante, C., White, J. C. (2012): Toxicity of silver and copper to Cucurbita pepo: Differential effects of nano and bulk-size particles. - Environmental Toxicology 27(9): 510-517.

[10] Mylle, E., Codreanu, M. C., Boruc, J., Russinova, E. (2013): Emission spectra profiling of fluorescent proteins in living plant cells. - Plant Methods 9(10): 1-8.

[11] Patlolla, A. K., Berry, A., May, L., Tchounwou, P. B. (2012): Genotoxicity of silver nanoparticles in Vicia faba: A pilot study on the environmental monitoring of nanoparticles. - International Journal of Environmental Research: Public Health 9: 16491662.

[12] Pokhrel, L. R., Dubey, B. (2013): Evaluation of developmental responses of two crop plants exposed to silver and zinc oxide nanoparticles. - Science of the Total Environment 452-453(2013): 321-332.

[13] Rao, N. K., Hanson, J., Dulloo, M. E., Ghosh, K., Nowell, D., Larinde, M. (2006): Manual of Seed Handling in Genebanks Manual of in Genebanks. - Bioversity International, Maccarese.

[14] Rico, C. M., Majumdar, S., Duarte-Gardea, M., Peralta-videa, J. R., Gardea-Torresdey, J. L. (2011): Interaction of nanoparticles with edible plants and their possible implications in the food chain. - Journal of Agriculture and Food Chemistry 58 (9): 3485-3498.

[15] Sintubin, L., Verstraete, W., and Boon, N. (2012): Biologically produced nanosilver: Current state and future perspectives. - Biotechnolgy and Bioengineering 109(10):242236.

[16] Strable, J., Scanlon, M. J. (2009): Maize (Zea mays L.):A model organism for basic and applied research in plant biology. - Cold Spring Harb Protocol 4(10):1-10.

[17] Thuesombat, P., Hannongbua, S., Akasit, S., Chadchawan, S. (2014):- Effect of silver nanoparticles on rice (Oryza sativa L. cv . KDML 105) seed germination and seedling growth. - Ecotoxicology and Environmental Safety 104: 302-309.

[18] Thul, S. T., Sarangi, B. K., Pandey, R. A. (2013): Nanotechnology in agroecosystem: Implications on plant productivity and its soil environment. - Expert Opinion on Environmental Biology 2(1).

[19] Varner, K. E., El-Badawy, A. Feldhake, D., Venkatapathy R. (2010): State-Of-TheScience Review: Everything NanoSilver and More. - EPA/600/R-10/084.

[20] Wang, J., Koo, Y., Alexander, A., Yang, Y., Westerhof, S., Zhang, Q., Schnoor, J. L., Colvin, V. L., Braam, J., Alvarez, P. J. J. (2013): Phytostimulation of Poplars and Arabidopsis exposed to silver nanoparticles and $\mathrm{Ag}^{+}$at sublethal concentrations. Environmental Science and Technology 47 (10): 5442-5449.

[21] Zhao, L., Peng, B., Hernandez-viezcas, J. A., Rico, C., Sun, Y., Peralta-videa, J. R. (2012): Stress response and tolerance of Zea maysL. to $\mathrm{CeO}_{2}$ nanoparticles: Cross talk among $\mathrm{H}_{2} \mathrm{O}_{2}$, heat shock protein, and lipid peroxidation. - ACS NANO 11: 9615-9622. 